\title{
Kinetic Studies of the Formation of Number of Spiropyrrolidine
}

\author{
Abdul Majeed M. Dabbagh Abdul Wahab J. Al-Hamdany Omar A. \\ Shareef \\ Department of Chemistry \\ College of Science \\ University of Mosul
}

Saphwan Al-Assaf

Glyndwr University

Wales-U.K.

(Received 11/10/2011;Accepted 21/11/2011)

\begin{abstract}
The rate of reaction between Schiff bases (N-Benzylidene-4-Picolyamine) and its derivatives with Chalcone(2-benzylidine-1-tetralone) to form spiropyrrolidine have been studied in DMF. This study occurred in two steps: The first step involved following the formation of intermediate by Fluorescence. The study indicated a pseudo first order dependence with rates 3,4-Dimethoxy $>$ p- $-\mathrm{OCH}_{3}>\mathrm{p}-\mathrm{CH}_{3}>\mathrm{H}>\mathrm{P}-\mathrm{Cl}>\mathrm{P}_{-} \mathrm{NO}_{2}$ at any temperature $(298-318 \mathrm{~K})$. The effect of substituents on the rate showed that electronic factors, inductive, conjugative and steric factors play reasonable role on the stability of the intermediates. The second step involved the disappearance of intermediate (cyclization process) to form the final product (spiropyrrolidine). This step was followed by UV technique and indicated a first order dependence with rates $\mathrm{P}_{-} \mathrm{NO}_{2}>\mathrm{p}-\mathrm{Cl}>\mathrm{H}>\mathrm{p}-\mathrm{CH}_{3}>\mathrm{p}-$ $\mathrm{OCH}_{3}>3$,4-Dimethoxy. A suitable mechanism for this type of reaction, which is consistent with the results, has been postulated.
\end{abstract}

Keywords: Spiropyrrolidine, Heterocyclic kinetic,1,3 anionic cycloaddition.

\section{درلسة حركية التكون عددمن للسبليرولينينات}

\section{المالغص}

مُ في هذا البحث قيلس معدلاتسرعة قفاعلات قواعدش يف ( N-Benzylidene-4-Picolyamine)

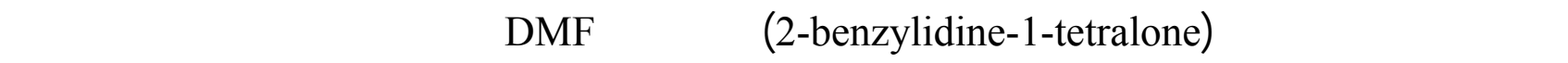

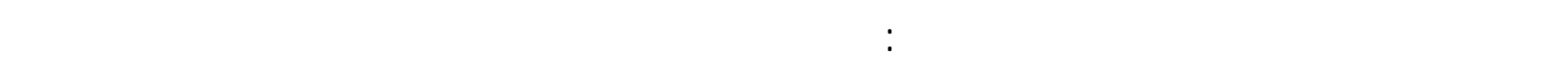

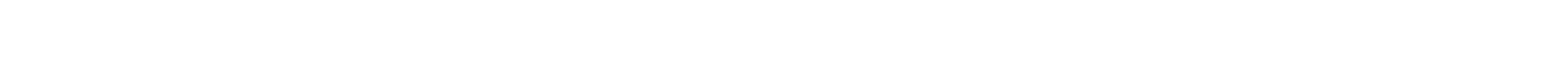
ويتباين معدل للسرعة وفةا للنسلسل التالي: 
3,4-Dimethoxy> p-OCH $>$ p-CH $-\mathrm{CH}>\mathrm{p}-\mathrm{Cl}>\mathrm{NO} \mathrm{NO}_{2}$ إله لن القاعل يتأثر بالهث والعولمل الإلكترونية الأخرى التي تسببها المعوضلت المختلفة وأن هذه العولمل تلعب دورا مهما بلسقرارية المركبت الوسطية، لما المرحلة الثانية فق فيها قيلسسررعة تحول ق المرك ـب

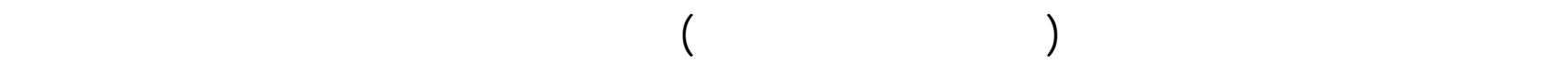

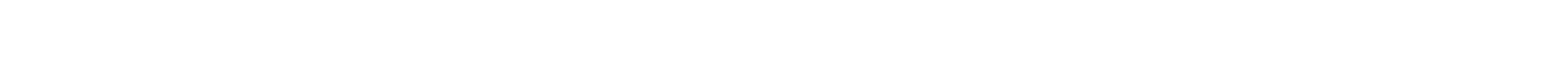

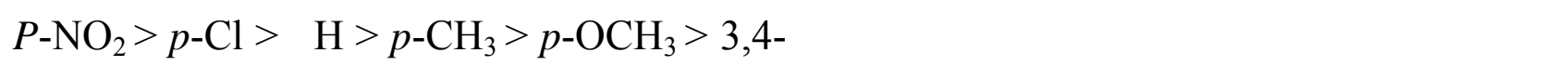
عimethoxy النتائج العملية.

\section{INTRODUCTION}

The addition of Schiff bases to $\alpha, \beta$ unsaturated ketones through a 1,3 anionic cyclo addition (Waldmann, 1995 ; Jayashankaran et al., 2005) via the formation of intermediate (Raj and Raghnathan, 2005); leading to the formation the pyrrolidines have not yet been studied and still remained somewhat obscure.

Here we report a first complete study on this process in highly basic DMF solution. The present work provides detailed and reliable information about the anionic cyclo addition of Schiff bases to chalcones, including Arrhenius parameters and entropies of activation.

Mechanism of the reaction process was proposed to explain the experimental observed rate laws and products formed with the aim of analyzing the influence of substituents in the phenyl ring of the chalcone and Schiff base on the stability of the suggested forming intermediate which led to the formation of the pyrrolidine products.

\section{Materials}

\section{EXPERIMENTAL}

All chalcones and Schiff bases were prepared in the department by a general procedure (Vogel, 1989). All organic compounds used for the syntheses were commercially available and purified before use. The DMF was of commercial grade as supplied by Fluka, $\mathrm{NaOH}$ was used as supplied by BDH limited, England.

\section{Kinetic measurements}

\section{First step: Formation of intermediate}

The reaction rates of this step were measured in this technique using DMF as solvent using fluorescence technique by determining the excitation absorbance $\left(\lambda_{\text {exc }}\right)$ and emission absorbance $\left(\lambda_{\mathrm{emi}}\right)$ for all compounds to obtain the best condition. Measurement was achieved by a PerkinElmer LS 45 .

The kinetic studies were carried out in special quartz cuvett cell. Prior to each kinetic run the reaction components (chalcone, Schiff base, sodium hydroxide) were placed separately in a water bath at the appropriate reaction temperature. The concentrations of the 
used Schiff base were always exactly 10 times as much as that of chalcone concentrations inside the reaction cell. To start a kinetic run, A solution of $1 \mathrm{ml}\left(1 \times 10^{-2} \mathrm{M}\right)$ Schiff base was then added with instant vigorous shaking at mixture consisted of $1 \mathrm{ml}$ of $\left(1 \times 10^{-3} \mathrm{M}\right)$ chalcone, and a $1 \mathrm{ml}$ of freshly prepared $0.01 \mathrm{M}$ sodium hydroxide, the reaction cell was then placed inside the spectrofluorometer immediately to start the measurements. Time was recorded automatically against intensity, repeated runs were always carried out (2-3) times to make sure of the consistent readings.

\section{Second Step: disappearance of intermediate (Cyclization process)}

The reaction rates were determined in DMF as solvent in range of $\lambda_{\max }(342-495 \mathrm{~nm})$ depending on the substituent of each reactant used. The kinetic studies were carried out in quartz cuvett, at the desired temperature of a Shimadzu UV-Visible spectrophotometer. A blank cell containing all reaction mixture with the appropriate concentration except that of chalcone was always used.

Repeated runs were always carried out (2-3) times to make sure of the consistency of measurements.

The Kinetic Measurements for both steps were carried at 5 different temperatures for each reaction and were always followed up to $\sim 75-85 \%$ completion of reaction.

The temperature was always controlled and maintained constant upto $\pm 0.1{ }^{\circ} \mathrm{C}$ during the reaction run.

$$
\begin{aligned}
& \operatorname{Ln}\left(\frac{A_{M}-A_{Q}}{A_{M}-A_{A_{2}}}\right)=k_{1} t \\
& \operatorname{Ln}\left(\frac{A_{M}-A_{z}}{A_{I_{z}}-A_{3 z}}\right)=k_{z} t
\end{aligned}
$$

(1) (For intermediate formation process)

(2) (For intermediate disappearance due to

cyclization process)

Where $k_{1}$ and $k_{2}$ represent the observed rate constants for the formation and disappearance of the intermediate. A refers to absorbance of intermediate and the subscript 0 refers to $\mathrm{t}=0$ (base line); $\mathrm{M}$ refers to the maximum absorbance of intermediate; $A_{t_{1}}$ and $A_{t_{2}}$ refer to the absorbance of formation and disappearance of intermediate at any time, while $A_{n}$ refers to the absorbance of intermediate at infinite time.

The standard error $\sigma$ of the slopes of a plot represents simply the uncertainty which is due to the scatter of the points about the regression line, and is thus a measure of the reproducibility of the result rather than its absolute value. Typical plots of the Chalcon (A) with Schiff base (B) are exhibited in Figs. 1 and 2. On the other hand tests were made for the real order of reactants A with B. Kinetic runs, at different concentrations of A were performed. Linear plots were obtained when the of $\log k_{1}$ vs $\log [\mathrm{B}]$ were demonstrated with slopes of unity proving, according to equation (5) a first order kinetics with respect to chalcones

$$
\log k_{1}=\log k+\mathrm{n} \log [\mathrm{A}]
$$

Hence a total $2^{\text {nd }}$ order kinetics for the formation of intermediate was confirmed. 
Arrhenius plots for both processes over were performed. The plots were straight lines. Arrhenius parameters and entropies of activation are tabulated in Table 5 and 6.

Rate constant for Formation of intermediate

Table 1a: Observed rate constants, for the reaction of chalcone with Schiff base B1 $(\mathrm{Y}=\mathrm{H}), \quad$ obtained from kinetic plots at different temperatures (formation of intermediate).

\begin{tabular}{|c|c|c|}
\hline Temp./K & $\mathbf{1 0}^{4} \mathbf{k} / \mathbf{s}^{-1}$ & $\mathbf{1 0}^{4} \boldsymbol{\sigma} / \mathbf{s}^{-1}$ \\
\hline 298 & 3.00 & 0.06 \\
\hline 303 & 4.51 & 0.07 \\
\hline 308 & 6.32 & 0.13 \\
\hline 313 & 8.54 & 0.12 \\
\hline
\end{tabular}

Table 1b: Observed rate constants, for the reaction of chalcone A20 with Schiff base $\mathrm{B2}\left(\mathrm{Y}=\mathrm{OCH}_{3}\right)$, obtained from kinetic plots at different temperatures (formation of intermediate).

\begin{tabular}{|c|c|c|}
\hline Temp./K & $\mathbf{1 0}^{\mathbf{4}} \mathbf{k} / \mathbf{s}^{-\mathbf{1}}$ & $\mathbf{1 0}^{\mathbf{4}} \boldsymbol{\sigma} / \mathbf{s}^{-\mathbf{1}}$ \\
\hline 298 & 9.06 & 0.43 \\
\hline 303 & 13.00 & 0.35 \\
\hline 308 & 19.71 & 0.92 \\
\hline 313 & 28.11 & 0.83 \\
\hline
\end{tabular}

Table 1c: Observed rate constants, for the reaction of chalcone with Schiff base $\mathrm{B3}\left(\mathrm{Y}=\mathrm{p}-\mathrm{NO}_{2}\right)$, obtained from kinetic plots at different temperatures (formation of intermediate).

\begin{tabular}{|c|c|c|}
\hline Temp./K & $\mathbf{1 0}^{\mathbf{4}} \mathbf{k} / \mathbf{s}^{-1}$ & $\mathbf{1 0}^{\mathbf{4}} \boldsymbol{\sigma} / \mathbf{s}^{-1}$ \\
\hline 298 & 0.97 & 0.03 \\
\hline 303 & 2.03 & 0.09 \\
\hline 308 & 4.10 & 0.18 \\
\hline 313 & 6.02 & 0.21 \\
\hline
\end{tabular}

Table 1d: Observed rate constants, for the reaction of chalcone with Schiff base B4 $(\mathrm{Y}=\mathrm{p}-\mathrm{Cl})$, obtained from kinetic plots at different temperatures (formation of intermediate).

\begin{tabular}{|c|c|c|}
\hline Temp./K & $\mathbf{1 0}^{\mathbf{4}} \mathbf{k} / \mathbf{s}^{-\mathbf{1}}$ & $\mathbf{1 0}^{\mathbf{4}} \boldsymbol{\sigma} / \mathbf{s}^{-\mathbf{1}}$ \\
\hline 298 & 0.81 & 0.02 \\
\hline 303 & 1.42 & 0.10 \\
\hline 308 & 5.13 & 0.15 \\
\hline 313 & 8.03 & 0.27 \\
\hline
\end{tabular}


Table 1 e: Observed rate constants, for the reaction of chalcone with Schiff base B5(Y=3,4-dimethoxy) obtained from kinetic plots at different temperatures(formation of intermediate).

\begin{tabular}{|c|c|c|}
\hline Temp./K & $\mathbf{1 0}^{\mathbf{4}} \mathbf{k} / \mathbf{s}^{-\mathbf{1}}$ & $\mathbf{1 0}^{\mathbf{4}} \boldsymbol{\sigma} / \mathbf{s}^{-\mathbf{1}}$ \\
\hline 298 & 45.18 & 1.72 \\
\hline 303 & 67.25 & 2.43 \\
\hline 308 & 96.08 & 3.52 \\
\hline 313 & 140.42 & 4.21 \\
\hline
\end{tabular}

Table (1 f): Observed rate constants, for the reaction of chalcone with Schiff base B6 $\left(\mathrm{Y}=\mathrm{p}-\mathrm{CH}_{3}\right)$ obtained from kinetic plots at different temperatures (formation of intermediate).

\begin{tabular}{|c|c|c|}
\hline Temp./K & $\mathbf{1 0}^{\mathbf{4}} \mathbf{k} / \mathbf{s}^{-\mathbf{1}}$ & $\mathbf{1 0}^{\mathbf{4}} \boldsymbol{\sigma} / \mathbf{s}^{-\mathbf{1}}$ \\
\hline 298 & 7.52 & 0.02 \\
\hline 303 & 12.51 & 0.68 \\
\hline 308 & 23.36 & 1.24 \\
\hline 313 & 39.20 & 1.59 \\
\hline
\end{tabular}




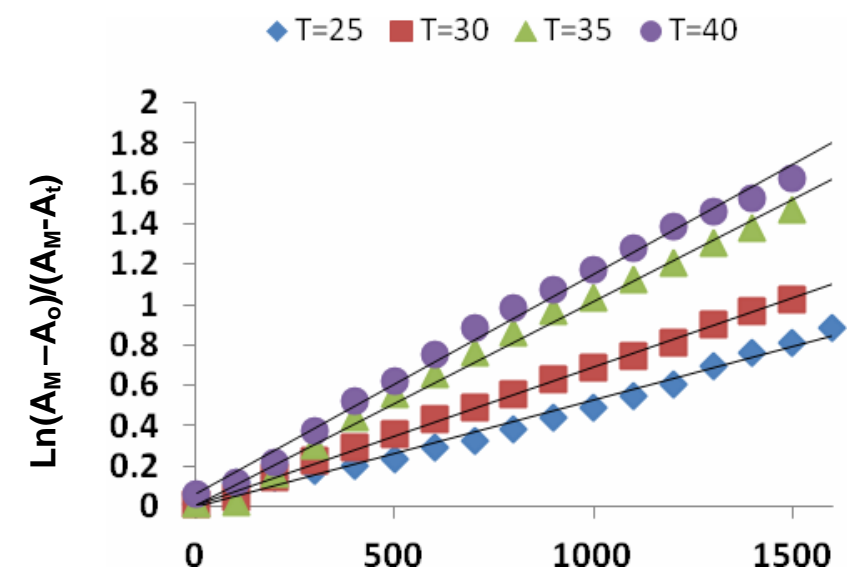

Fig.(1a): Pseudo 1st order plot for formation of the intermediate from the reaction between chalcone with the Schiff base B1 in DMF at different

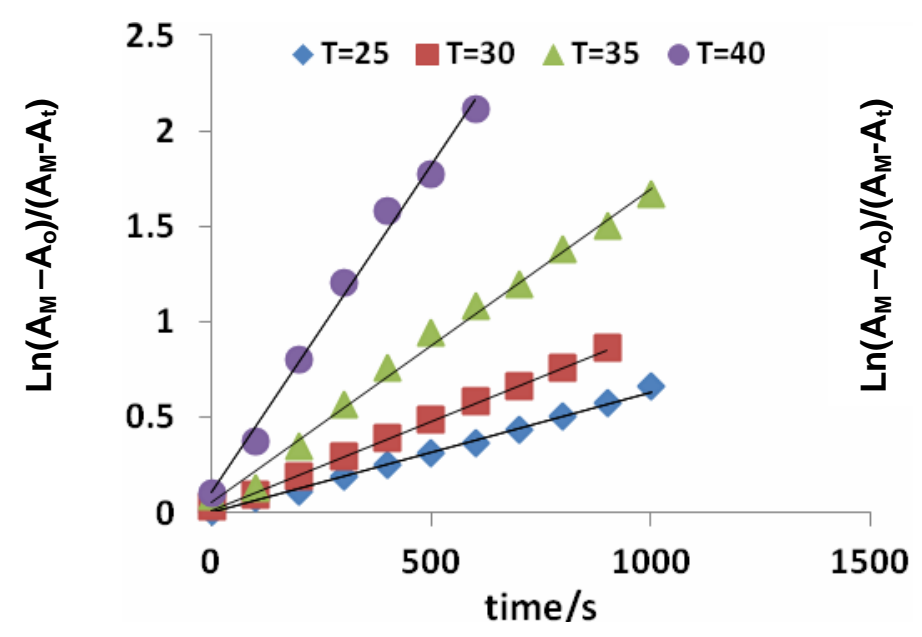

Fig.(1c): Pseudo 1st order plot for formation of the intermediate from the reaction between chalcone with the Schiff base B1 in DMF at different

$$
\leftrightarrow \mathrm{T}=\mathbf{2 5} \square \mathrm{T}=\mathbf{3 0} \triangle \mathrm{T}=\mathbf{3 5} \bullet \mathrm{T}=\mathbf{4 0}
$$

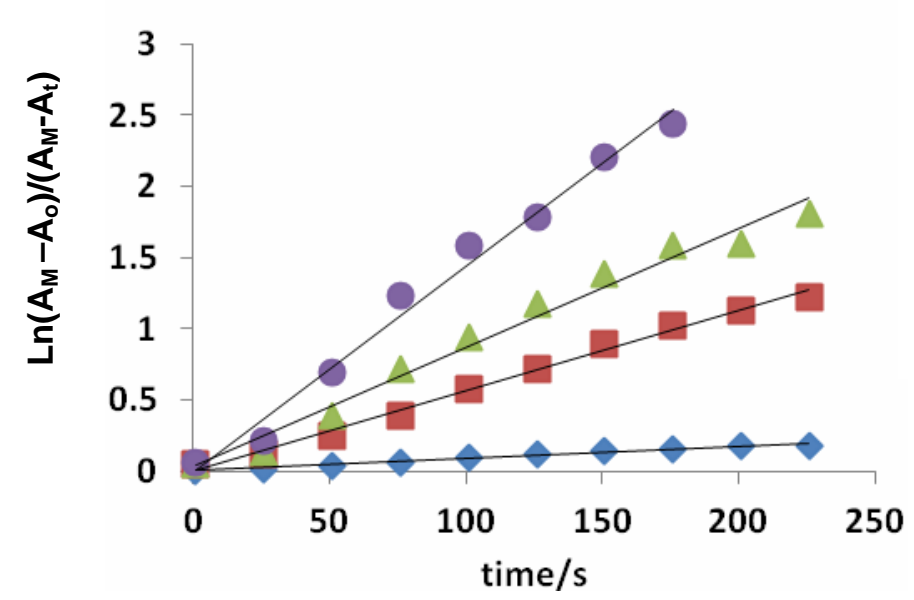

Fig.(1e): Pseudo 1st order plot for formation of the intermediate from the reaction between chalcone with the Schiff base B5 in DMF at different

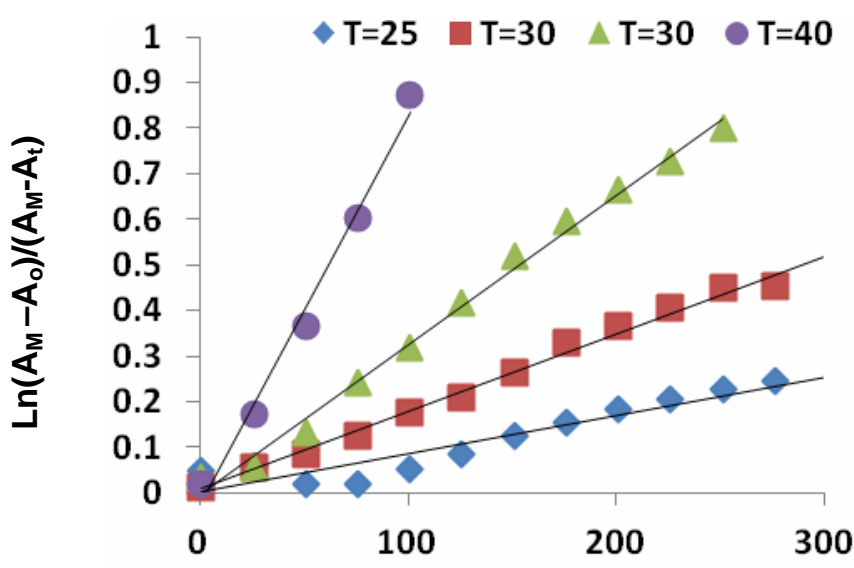

Fig.(1b): Pseudo 1st order plot for formation of the intermediate from the reaction between chalcone with the Schiff base $B 2$ in DMF at different

$\leftrightarrow \mathrm{T}=\mathbf{2 5} \square \mathrm{T}=30 \Delta \mathrm{T}=35 \quad \mathrm{~T}=40$

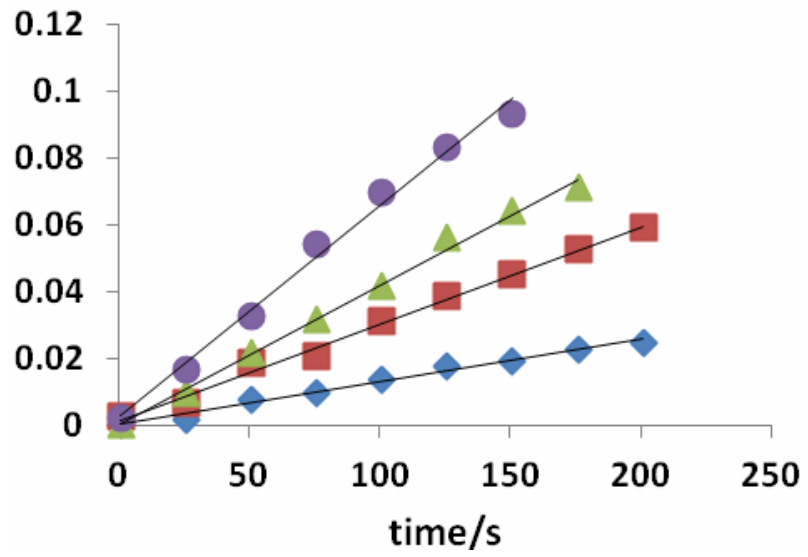

Fig.(1d): Pseudo 1st order plot for formation of the intermediate from the reaction between chalcone with the Schiff base B4 in DMF at different

$$
\Delta \mathrm{T}=\mathbf{2 5} \square \mathrm{T}=\mathbf{3 0} \Delta \mathrm{T}=\mathbf{3 5} \bullet \mathrm{T}=\mathbf{4 0}
$$

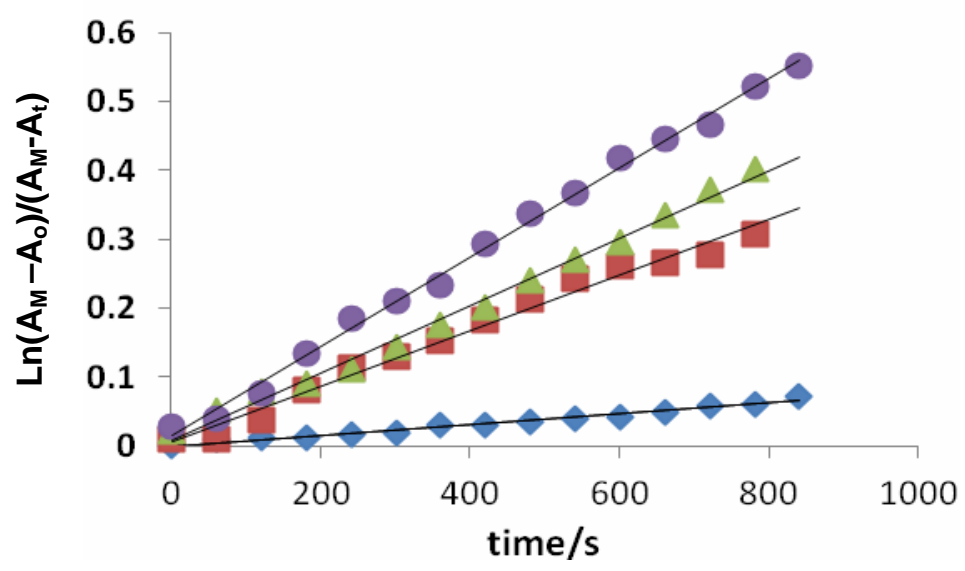

Fig.(1f): Pseudo 1st order plot for formation of the intermediate from the reaction between chalcone with the Schiff base $B 6$ in DMF at different 
intermediate

Table 2a: Observed rate constants, for the reaction of chalcone with Schiff base B1, obtained from kinetic plots at different temperatures (disappearance of intermediate).

\begin{tabular}{|c|c|c|}
\hline Temp./K & $\mathbf{1 0}^{\mathbf{2}} \mathbf{~} / \mathbf{m i n}^{-1}$ & $\mathbf{1 0}^{\mathbf{2}} \mathbf{\sigma} \mathbf{m i n}^{-\mathbf{1}}$ \\
\hline 298 & 2.323 & 0.017 \\
\hline 303 & 2.726 & 0.034 \\
\hline 308 & 3.309 & 0.072 \\
\hline 313 & $\mathbf{4 . 3 6 0}$ & $\mathbf{0 . 0 8 7}$ \\
\hline 318 & 5.166 & 0.098 \\
\hline
\end{tabular}

Table 2b: Observed rate constants, for the reaction of chalcone with Schiff base B2, obtained from kinetic plots at different temperatures (disappearance of intermediate).

\begin{tabular}{|c|c|c|}
\hline Temp./K & $\mathbf{1 0}^{2} \mathbf{~} / \mathbf{m i n}^{-\mathbf{1}}$ & $\mathbf{1 0}^{\mathbf{2}} \mathbf{\sigma} \mathbf{m i n}^{\mathbf{- 1}}$ \\
\hline 298 & 1.320 & 0.027 \\
\hline 303 & 2.264 & 0.036 \\
\hline 308 & 2.895 & 0.046 \\
\hline 313 & $\mathbf{3 . 5 7 4}$ & $\mathbf{0 . 0 6 7}$ \\
\hline 318 & 4.319 & 0.083 \\
\hline
\end{tabular}

Table 2c: Observed rate constants, for the reaction of chalcone with Schiff base B3, obtained from kinetic plots at different temperatures (disappearance of intermediate).

\begin{tabular}{|c|c|c|}
\hline Temp./K & $\mathbf{1 0}^{2} \mathbf{k} / \mathbf{m i n}^{-\mathbf{1}}$ & $\mathbf{1 0}^{\mathbf{2}} \mathbf{\sigma} \mathbf{m i n}^{\mathbf{- 1}}$ \\
\hline 298 & 4.049 & 0.048 \\
\hline 303 & 5.870 & 0.059 \\
\hline 308 & 6.075 & 0.072 \\
\hline 313 & $\mathbf{7 . 8 0 2}$ & $\mathbf{0 . 1 3 0}$ \\
\hline 318 & 9.151 & 0.216 \\
\hline
\end{tabular}

Table 2d: Observed rate constants, for the reaction of chalcone with Schiff base B4, obtained from kinetic plots at different temperatures (disappearance of intermediate).

\begin{tabular}{|c|c|c|}
\hline Temp./K & $\mathbf{1 0}^{2} \mathbf{~ k} / \mathbf{m i n}^{-1}$ & $\mathbf{1 0}^{\mathbf{2}} \mathbf{\sigma} / \mathbf{m i n}^{-\mathbf{1}}$ \\
\hline 298 & 2.293 & 0.044 \\
\hline 303 & 3.132 & 0.068 \\
\hline 308 & 3.814 & 0.098 \\
\hline 313 & $\mathbf{4 . 7 0 0}$ & $\mathbf{0 . 0 6 8}$ \\
\hline 318 & 5.439 & 0.171 \\
\hline
\end{tabular}


Table 2e: Observed rate constants, for the reaction of chalcone A20 with Schiff base B5, obtained from kinetic plots at different temperatures (disappearance of intermediate).

\begin{tabular}{|c|c|c|}
\hline Temp./K & $\mathbf{1 0}^{\mathbf{2}} \mathbf{k} / \mathbf{m i n}^{-\mathbf{1}}$ & $\mathbf{1 0}^{\mathbf{2}} \mathbf{\sigma} / \mathbf{m i n}^{-\mathbf{1}}$ \\
\hline 298 & 1.495 & 0.032 \\
\hline 303 & 2.157 & 0.029 \\
\hline 308 & 2.270 & 0.035 \\
\hline 313 & $\mathbf{3 . 0 3 5}$ & $\mathbf{0 . 0 6 5}$ \\
\hline 318 & 3.724 & 0.112 \\
\hline
\end{tabular}

Table 2f: Observed rate constants, for the reaction of chalcone with Schiff base B6, obtained from kinetic plots at different temperatures (disappearance of intermediate).

\begin{tabular}{|c|c|c|}
\hline Temp./K & $\mathbf{1 0}^{\mathbf{2}} \mathbf{~} / \mathbf{m i n}^{-\mathbf{1}}$ & $\mathbf{1 0}^{\mathbf{2}} \mathbf{\sigma} \mathbf{m i n}^{\mathbf{- 1}}$ \\
\hline 298 & 1.975 & 0.027 \\
\hline 303 & 2.396 & 0.077 \\
\hline 308 & 2.965 & 0.047 \\
\hline 313 & $\mathbf{4 . 1 2 0}$ & $\mathbf{0 . 0 9 1}$ \\
\hline 318 & 5.228 & 0.115 \\
\hline
\end{tabular}

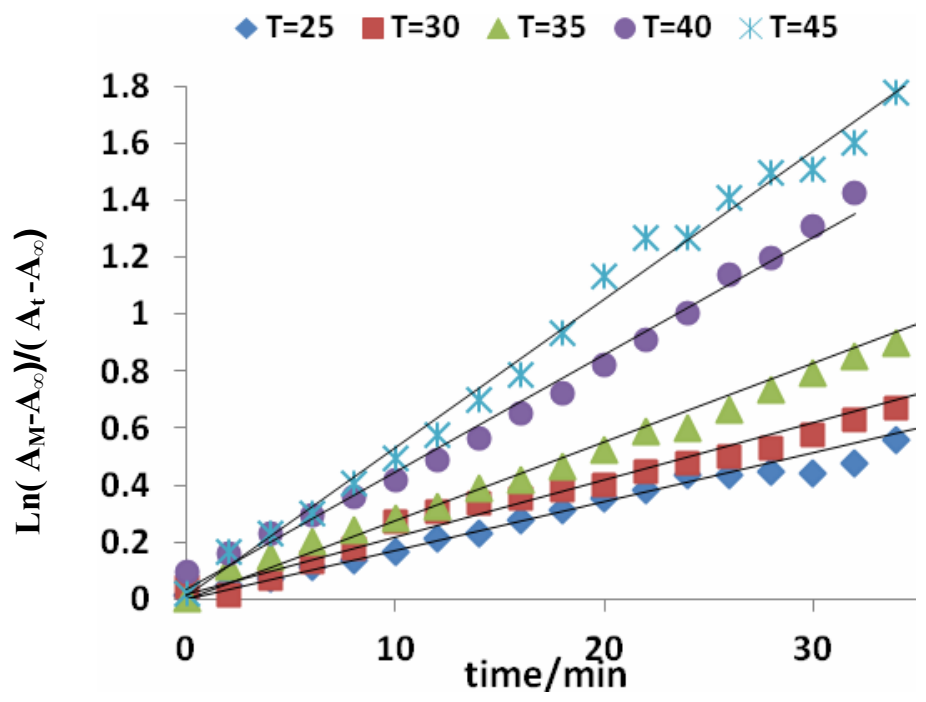

Fig. 2a: First order plot for the cyclization of intermediate from the reaction between chalcone with the Schiff base $B 1$ in DMF at different temperatures

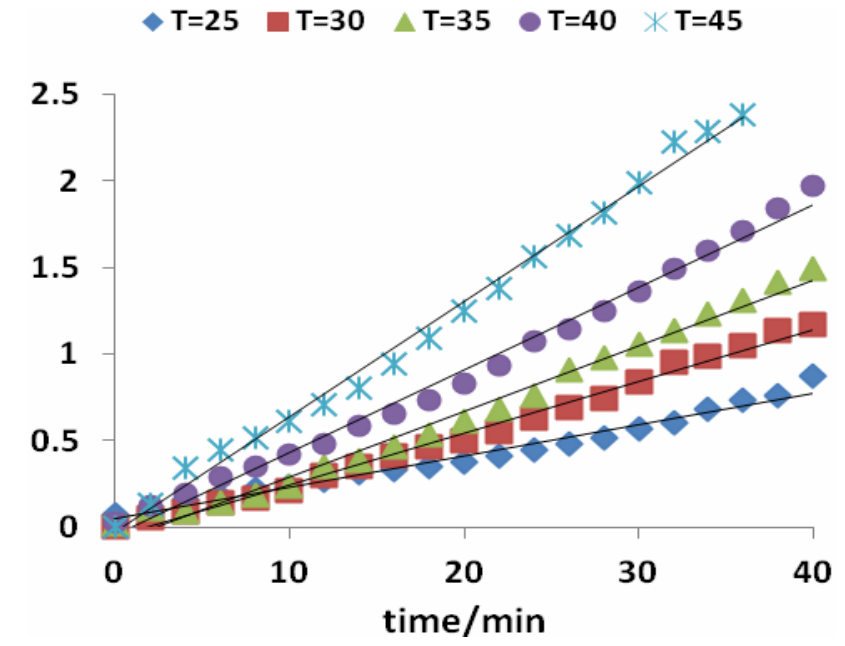

Fig. 2b: First order plot for the cyclization of intermediate from the reaction between chalcone with the Schiff base $B 2$ in DMF at different temperatures 


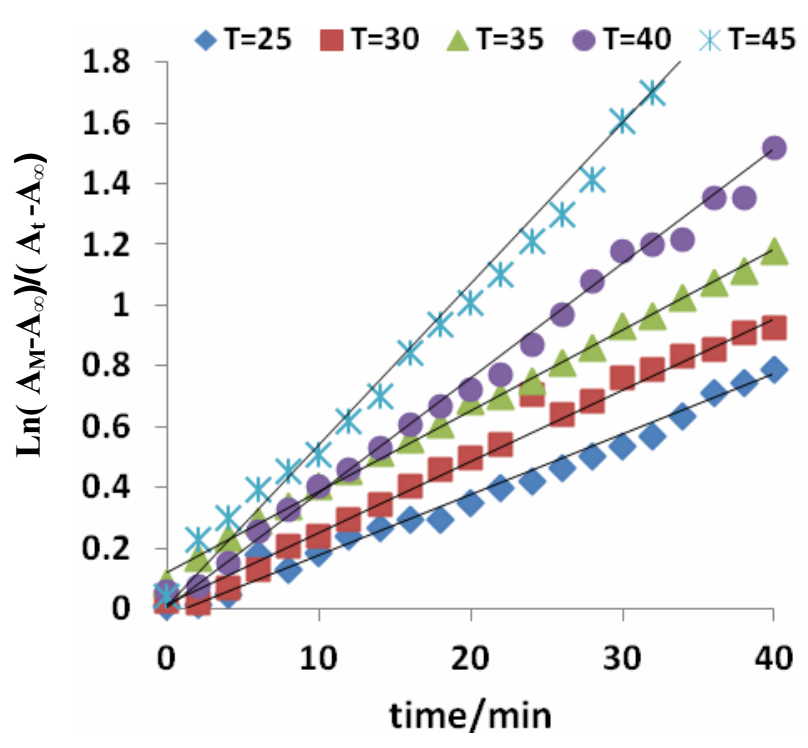

Fig. 2c: First order plot for the cyclization of intermediate from the reaction between chalcone with the Schiff base $B 3$ in DMF at different temperatures

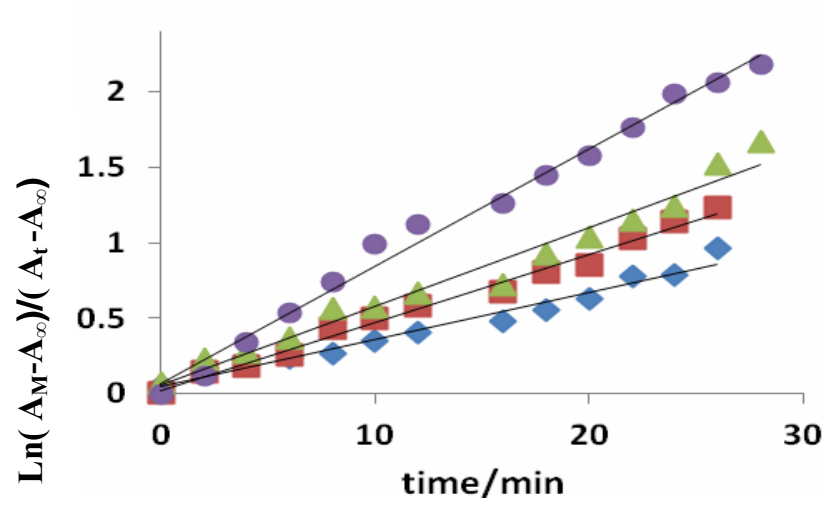

Fig. 2e: First order plot for the cyclization of intermediate from the reaction between chalcone with the Schiff base B5 in DMF at different temperatures

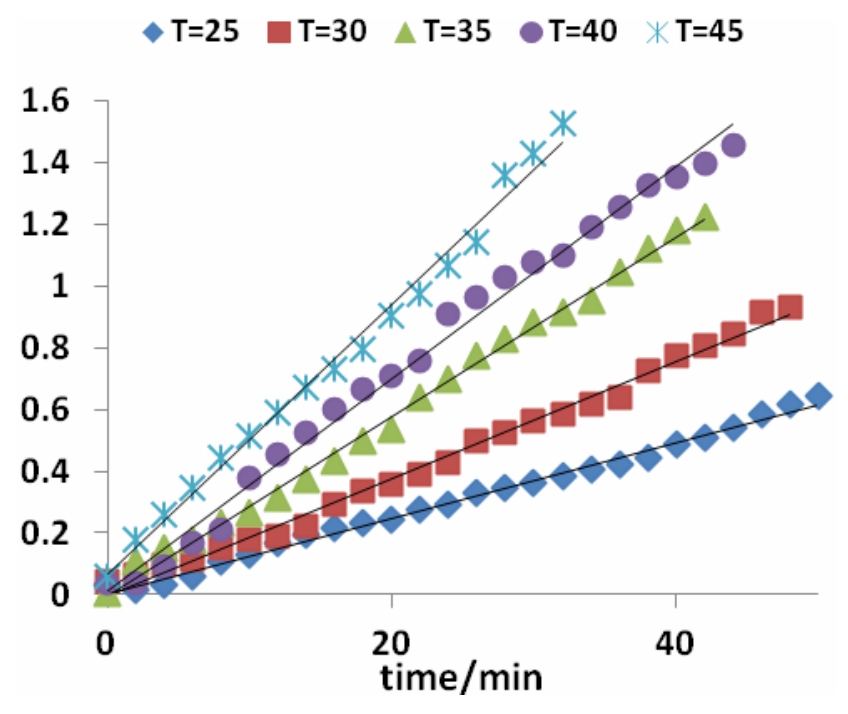

Fig.(2d): First order plot for the cyclization of intermediate from the reaction between chalcone with the Schiff base B4 in DMF at

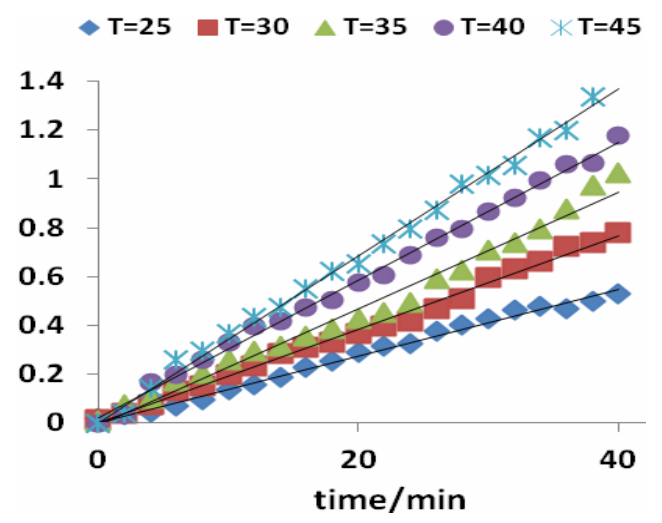

Fig. 2f: First order plot for the cyclization of intermediate from the reaction between chalcone with the Schiff base B6 in DMF at different temperatures

\section{DISCUSSION}

\section{Part One: Formation of intermediate (followed by Fluorescence)}

During our search for a suitable peak, in the fluorescence region it was noticed that a nice band attributed to the formation of the intermediate was built up systematically in both of excitation [absorbance at (300-420) nm] and emission [absorbance at (385-537) nm] regions depending on the substituent used in chalcone moiety. Therefore, kinetic investigation was followed taking these new bands into account.

Preliminary experiments showed that reasonable rates of the anionic addition were obtained at a temperature range between (298-313K). No compounds other than A, B and 
product were ever detected in the isolated product of these reactions as confirmed by Fluorescence, IR and NMR. But the intermediate was detected by Fluorescence during analysis under kinetic conditions. Typical runs of reaction toward completion demonstrate very clearly how the absorbance of the intermediate at infinite time, does not change its value and position when temperature is changed indicating that the reaction is completely forward and no equilibrium between intermediate, $\mathrm{A}$ and $\mathrm{B}$ from one side and between intermediate and final product from the other side is ever existed.

For the parent chalcone $(\mathrm{X}=\mathrm{H})$, reacting with different substituted Schiff bases (B1B6) involving ( $\mathrm{Y}=\mathrm{H}, \mathrm{p}-\mathrm{OCH}_{3}, \mathrm{p}-\mathrm{NO}_{2}, \mathrm{p}-\mathrm{Cl}, 3,4-$ dimethoxy, $\mathrm{p}-\mathrm{CH}_{3}$ ) respectively. For this group the electronic effects of the substituent of the attacking Schiff base play important role in enhancing or reducing the rate of reaction in comparison with the corresponding parent reactants $(\mathrm{X}=\mathrm{H}),(\mathrm{Y}=\mathrm{H})$ at $308 \mathrm{~K}$.

The rate of reaction increases as the electronegativity of Schiff base nucleophile increases. The differences in the rates are in the following order

3,4-Dimethoxy $>$ p-OCH $3>$ p- $\mathrm{CH}_{3}>\mathrm{H}>\mathrm{P}-\mathrm{Cl}>\mathrm{P}-\mathrm{NO}_{2}$

Table 3: The rate of formation of intermediate for different substituents

\begin{tabular}{|c|c|c|c|c|c|c|}
\hline $\begin{array}{c}\text { Y } \\
\text { Substituents }\end{array}$ & $\mathrm{H}$ & $p-\mathrm{OCH}_{3}$ & $\mathrm{P}-\mathrm{NO}_{2}$ & $P-\mathrm{Cl}$ & $\begin{array}{c}3,4-\mathrm{Di}- \\
\mathrm{OCH}_{3}\end{array}$ & $p-\mathrm{CH}_{3}$ \\
\hline $\mathbf{1 0}^{\mathbf{4}} \mathbf{k} / \mathbf{s}^{-\mathbf{1}}$ & 6.3 & 23.0 & 4.0 & 5.0 & 96.0 & 19.0 \\
\hline $\mathbf{t}_{\mathbf{1} / \mathbf{2}} / \mathbf{s}$ & 1100.0 & 301.3 & 1732.5 & 1386.0 & 72.1 & 364.7 \\
\hline
\end{tabular}

The sequence of arrangements indicate that electron donating groups such as 3,4 di- $-\mathrm{OCH}_{3}, \mathrm{p}-\mathrm{OCH}_{3}$ and $\mathrm{p}-\mathrm{CH}_{3}$ enhance the rate of reaction. These substituents enrich the electron density of the Schiff base nucleophile, thus providing a better chance for it to attack the chalcone, resulting in a relatively acceleration of reaction rate. On the other hand electron withdrawing groups such as $\left(\mathrm{p}-\mathrm{NO}_{2}, \mathrm{p}-\mathrm{Cl}\right)$ reduce the rate. These substituents pauperize the electron density of the nucleophile resulting in a consequent decrease of the rate, as discussed in the following manner:

The rate of the parent reaction $\mathrm{X}=\mathrm{Y}=\mathrm{H}$ was taken as a reference for comparison $\left(\mathrm{t}_{1 / 2}=\right.$ $1100 \mathrm{~s}$ ). For $\mathrm{X}=\mathrm{H}, \mathrm{Y}=\mathrm{OCH} 3$ the methoxy group is an electron donating group, thus enriches the nucleophlicity of the Schiff base nucleophile by increasing its electron density and increase the inter-attractive forces between chalcone and Schiff base nucleophile. As a result the rate of formation of intermediate is increased i.e $t_{1 / 2}$ decreased $\left(t_{1 / 2}=301 \mathrm{~s}\right)$. While for $\mathrm{X}=\mathrm{H}, \mathrm{Y}=3,4$-dimethoxy. The 3,4-dimethoxy group (B5) acts better than the $\mathrm{p}-\mathrm{OCH}_{3}$ itself in enriching the electron density on the Schiff base nucleophile and increases the possibility of attacking the reaction centre of the chalcone, thus enhancing the rate of the formation of the intermediate, even more than that of the methoxy group itself, $\left(\mathrm{t}_{1 / 2}=72 \mathrm{~s}\right)$. furthermore when $\left(\mathrm{Y}=\mathrm{p}-\mathrm{CH}_{3}\right)$ The p-methyl substituent also increase the rate of formation of intermediate as compared with corresponding unsubstitued analogue $(\mathrm{H})$ due to the donation of electrons through hyperconjugation effect. As a result the reaction rate is increased, but still slower than with case of methoxy group or dimethoxy group $\left(\mathrm{t}_{1 / 2}=364 \mathrm{~s}\right)$. 
But when $\mathrm{X}=\mathrm{H}, \mathrm{Y}=\mathrm{p}-\mathrm{NO}_{2}$ the nitro group is an electron withdrawing group, it reduced electron density of the Schiff base nucleophile, thus providing a lower chance for its attack to the reaction centre of chalcone to complete formation of intermediate, resulting in relative deceleration of reaction rate, $\mathrm{t}_{1 / 2}=1732 \mathrm{~s}$. On the other hand when a p-chloro substituent is used at $\mathrm{X}=\mathrm{H}, \mathrm{Y}=\mathrm{Cl}$, the rate of reaction is also decreased but not as much as that of $\left(\mathrm{p}-\mathrm{NO}_{2}\right)$ group, due to the behavior of chloro substituent as an electron donating and withdrawing group at the same time with net electron withdrawing behavior. As a result its rate becomes in between the corresponding parent reactants and $p-\mathrm{NO}_{2}$ analogues $t_{1 / 2}=1386 \mathrm{~s}$.

It is then concluded that the electron donating groups increase the chance of attacking the azallylanion (nucleophile) to the reaction centre of chalcone, resulting in a faster rate of reaction.

\section{Part Two: Disappearance of intermediate (Cyclization process) (followed by UV)}

These reactions are clean forward processes, since no equilibrium was observed during kinetic runs and no compounds other than the suggested intermediate were even detected during kinetic measurements. Typical runs of reaction toward completion were followed by UV-Visible technique at 298-18 K, the reaction was found to be completely forward and no equilibrium between reactants, intermediate and product was ever detected even at infinite time.

The reactions between the Schiff bases and chalcones toward the formation and disappearance of the suggested intermediate to the pyrolidine products were found to obey the bimolecular pseudo 1 st order and a unimolecular $1^{\text {st }}$ functions respectively, leading to linear plots. Furthermore, plots demonstrate very good agreement between repeated runs. On the other hand a test was made for the total order of reaction for the process $\mathrm{A}+\mathrm{B} \longrightarrow \mathrm{C}$ as shown in scheme (1) in addition to the 1 st order reaction for the process $\mathrm{C} \longrightarrow \mathrm{D}$, so that the full scheme of the reaction $\mathrm{A}+\mathrm{B} \longrightarrow \mathrm{C} \longrightarrow \mathrm{D}$ was established and confirmed. 


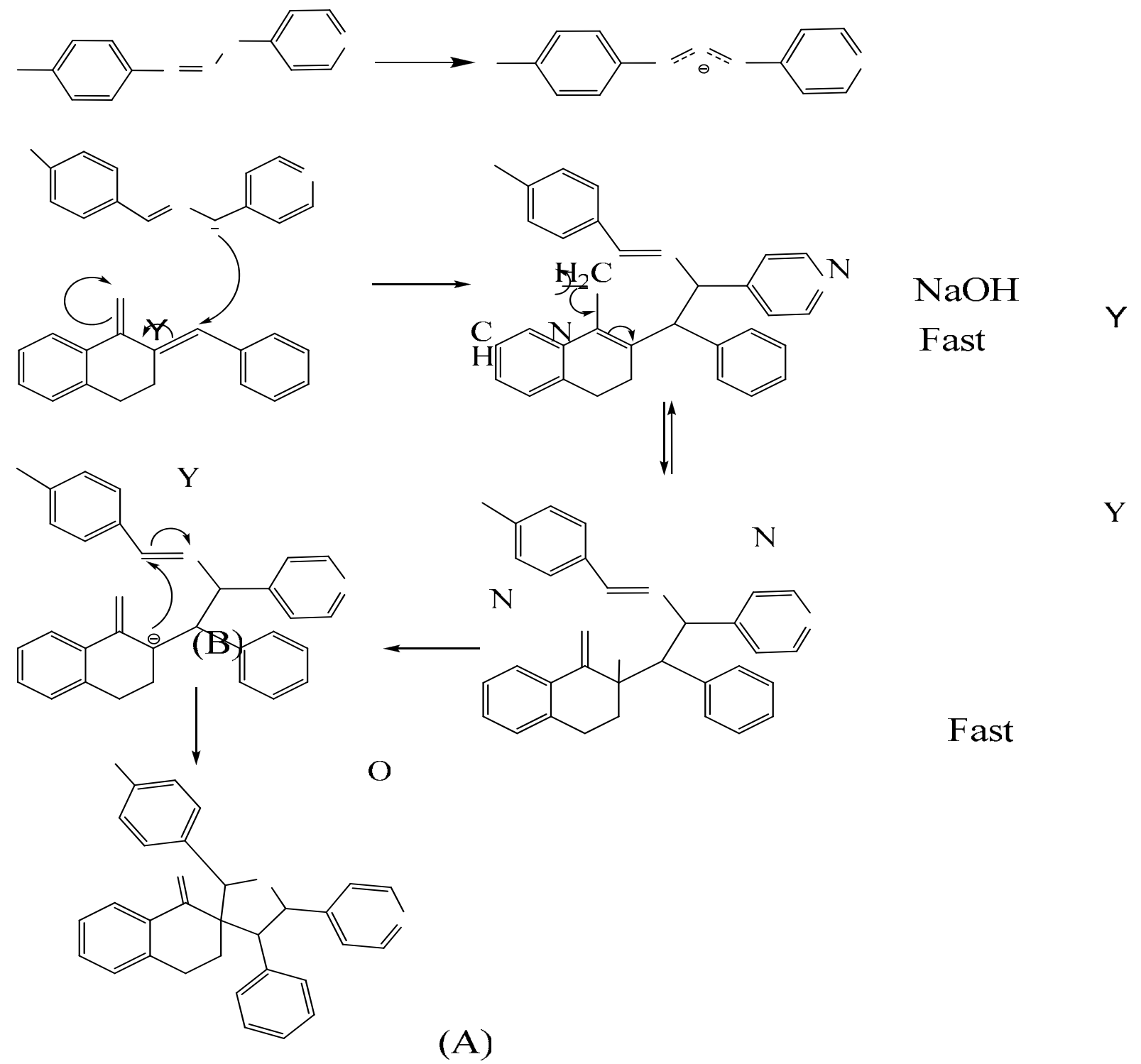

Y

Scheme (1)

The reaction between the chalcone and Schiff base may be explained in the following suggested 1,3-Anionic cycloaddition manner.

The chalcone molecule which is an $\alpha, \beta$-unsaturated ketone always exists in a resonance form in order to stabilize itself so that a partial positive charge on the reaction centre $\beta$-carbon is obtained. $\mathrm{O}$

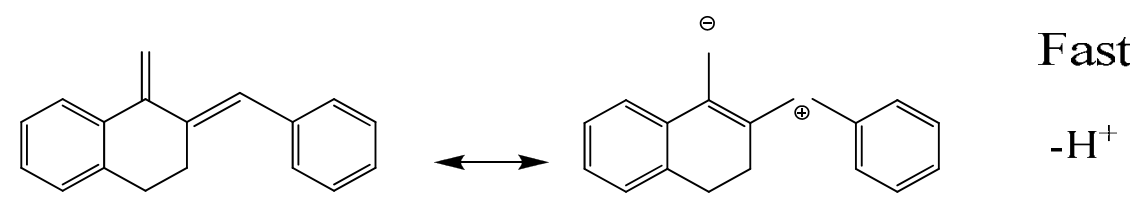

In this case, the nucleophile sltacks the chalcone at $\beta$-carbon in a retevely fast step to form the intermediate $C$ ( $\beta$-(2-Arylideneaminid) $H_{\text {transfer }}^{+} 1$-aryl-2-(pyridine-4-yl)ethyl- $\alpha$-tetralone). 
The basic medium offers a good chance for the Schiff base to become a nucleophile by abstraction of the most acidic proton on the carbon next to $\gamma$ position of pyridine ring. In this case the Schiff base gets ionized in a fast step and a nuclophile is obtained (Joule and Mills, 2010). This observation was confirmed by UV spectroscopy as the Schiff base bond was immediately disappeared by addition of $\mathrm{NaOH}$.
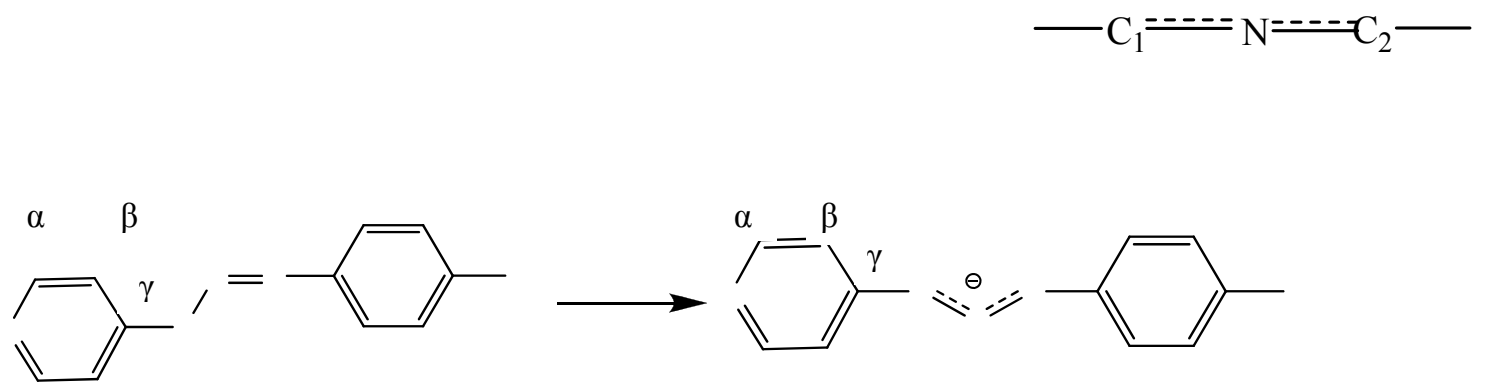

The above mentioned Schiff base nucleophile (azaally anion) is unsymmetrical due to the existence of the pyridyle aryl group on both sides of the system, so that the density of the negative charge may localize itself on one side more than the other. In fact the -ve charge concentrates on the $\mathrm{C}_{1}$ atom which is next to $\gamma$ position of the pyridine ring due to resonance of enaminate anion rather the other side $\mathrm{C}_{2}$ which is next to the aryl ring. For this reason, the 1,3 anionic attack leading to the formation of five membered ring must start from the more negative $\mathrm{C}_{1}$ side.

In fact a 1,3-anionic cycloaddition of azaallyl anion leading to five-membered nitrogen heterocycles was pioneered by Kauffmann (Kauffmann et al., 1970). The carbanion may cyclize itself by attacking the olefinic carbon in a slow step to form the 5-membered heterocyclic compound (Spiropyrrolidine).

The differences in rate constants are qualitatively explicable in terms of nuclophilic nature of the Schiff base that attacks the chalcone, and in addition to the availability of the + ve charge on the $\beta$-carbon site. Moreover, the combined inductive and conjugative effects of the substituents on the (chalcone or Sqhiff bases) and their intermediate malatso play aN important role in explaining the differences in rates. It is also important to introduce a unique opportunity to interpret our'kinetic results in terms of a factor caused by the rotation around the new formed single bond of the intermediate which causes the exposure of the $\mathrm{Sp}^{2}$ hybridized carbon to the nucleophilic attack. This rotational process may cause the delay of the cyclization process of intermediate to form the pyrrolydine, and increases its half life.

The reaction also involved different substituents $\left(\mathrm{Y}=\mathrm{H}, \mathrm{p}-\mathrm{OCH}_{3}, \mathrm{P}-\mathrm{NO}_{2}, \mathrm{P}-\mathrm{Cl}\right.$, 3,4-Dimethoxy, $\mathrm{p}-\mathrm{CH}_{3}$ ). It is for this group of reactants that electronic effects of the substituents play important role in affecting the rate of this process, since they either enrich or pauperize the reaction centre with electrons.

The differences in rates for these groups were found to be in the following order of:

$P-\mathrm{NO}_{2}>p-\mathrm{Cl}>\mathrm{H}>p-\mathrm{CH}_{3}>p-\mathrm{OCH}_{3}>3,4-$ Dimethoxy 
Table 4: The rate of disappearance of intermediate for different substituents.

\begin{tabular}{|c|c|c|c|c|c|c|}
\hline $\begin{array}{c}\mathrm{Y} \\
\text { Substituents }\end{array}$ & $\mathrm{H}$ & $p-\mathrm{OCH}_{3}$ & $\mathrm{P}-\mathrm{NO}_{2}$ & $P-\mathrm{Cl}$ & $3,4-\mathrm{Di}-\mathrm{OCH}_{3}$ & $p-\mathrm{CH}_{3}$ \\
\hline $\mathbf{1 0}^{\mathbf{4}} \mathbf{k} / \mathbf{s}^{-\mathbf{1}}$ & 4.36 & 3.57 & 7.80 & 4.70 & 3.05 & 4.12 \\
\hline $\mathbf{t}_{\mathbf{1} / \mathbf{2}} / \mathbf{s}$ & 15.89 & 19.39 & 8.85 & 14.74 & 22.72 & 16.82 \\
\hline
\end{tabular}

The unsubstituted functional group for reaction between chalcone, $\mathrm{X}=\mathrm{H}$, with Schiff base, (B1) $\mathrm{Y}=\mathrm{H}$, was taken as a reference reaction rate for comparison $\left(\mathrm{t}_{1 / 2}=15.89 \mathrm{~min}\right)$.

When $(\mathrm{Y}=\mathrm{OCH} 3)$ the methoxy group is an electron donating group, thus enriches the reaction centre of the formed intermediate, by increasing its electron density at the reaction centre, thus increasing the intra-repulsive force of the cyclization. As a result the rate of reaction is decreased and $t_{1 / 2}$ increased $\left(t_{1 / 2}=19.39 \mathrm{~min}\right)$. Furthermore $(Y=3,4$-Dimethoxy) another electron donating group is used. The 3,4-dimethoxy group (B5) enriches the electron density at the intermediate more than the $\mathrm{p}-\mathrm{OCH}_{3}$ itself, and decreases the possibility of attacking the reaction centre of intermediate, thus reducing the rate, even more than that of the methoxy group itself, $\left(\mathrm{t}_{1 / 2}=22.72 \mathrm{~min}\right)$.

For $\left(\mathrm{Y}=\mathrm{CH}_{3}\right)$ another donating group, The p-methyl substituent also delay the rate of reaction as compared with corresponding unsubstitued analogue $(\mathrm{H})$ due to the donation of electrons by hyperconjugation effect. As a result the reaction rate is delayed, but still faster than with case of methoxy group or dimethoxy group table $3(\mathrm{a}-\mathrm{e})\left(\mathrm{t}_{1 / 2}=16.82 \mathrm{~min}\right)$.

On the other hand the nitro group is an electron withdrawing group $\mathrm{Y}=\mathrm{NO}_{2}$, it reduced electron density at the reaction centre of the intermediate, thus provided a higher chance for a faster cyclization process to occur, resulting in relative acceleration of reaction rate, $\mathrm{t}_{1 / 2}=8.85 \mathrm{~min}$. Finally when $(\mathrm{Y}=\mathrm{Cl})$ when a p-chloro substituent is used, the rate of reaction is also increased but not as much as that of $\left(\mathrm{NO}_{2}\right)$ group, due to the behavior of chloro substituent as an electron donating and withdrawing group at the same time. As a result its rate becomes in, between the corresponding $\mathrm{H}$ and $p-\mathrm{NO}_{2}$ analogues $\mathrm{t}_{1 / 2}=14.74 \mathrm{~min}$.

\section{Activation Parameters for the formation of intermediate}

The values of activation parameters Table (5) is of great importance to discern the mechanism under all circumstances of the study.

In our case, and because that the reaction mechanism consists two consecutive slow steps, i.e,

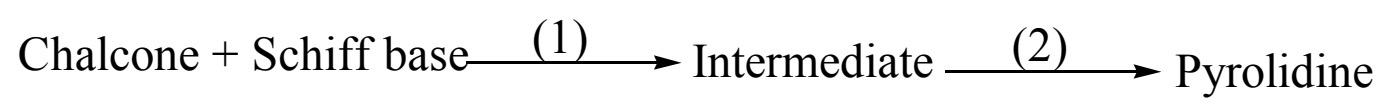

Studies of the rates of these two processes at different temperatures ( formation of the intermediate and its decay to form the product) enable us to find their activation energies $\mathrm{E}_{1}$, which is required for the bond linkage between the chalcone and Schiff base and $E_{2}$ which is required for cyclization of the intermediate to form the pyrrolidine. The variation in their values may be attributed to electronic factors supported by substituent groups. 
The formation of many five-membered heterocycles including pyrrolidine can be proceeded through a $(3+2)$ cycloaddition of allyl anions and olefins. (Pearson et al., 1992), (Kleingeld et al., 1984). Two mechanistic routes were suggested; a concerted $\left(4 \pi_{\mathrm{s}}+2 \pi_{\mathrm{s}}\right)$ cycloaddition mechanism, which must be a symmetry allowed according to Woodward Hoffmann rules, (Woodward and Hoffmann, 1969) and an alternative two step pathway involving the formation of an intermediate, such as that which is suggested for our reactions under study. Computational studies showed that the $\left(4 \pi_{\mathrm{s}}+2 \pi_{\mathrm{s}}\right)$ mechanism, which is expected on the basis of Woodward -Hoffmann rules, is energetically less favorable than the two-step pathways (Powers et al., 1998). The two step pathway is incompatible mechanism with a stereospecific or non stereospecific reaction course, as outlined in the following scheme 3 .

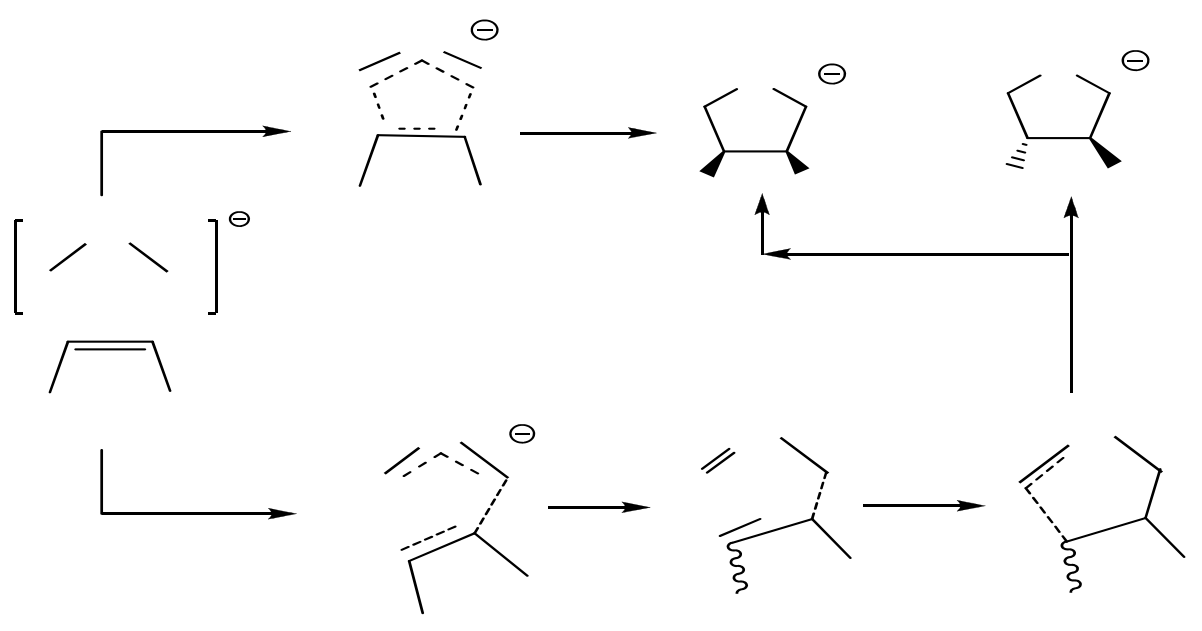

Scheme (2)

Table 5: Arrhenius parameters and entropies of activation for the reaction of Chalcone with Schiff base (B1-,B6) to form intermediatestep1

\begin{tabular}{|c|c|c|c|}
\hline $\begin{array}{c}\text { Reaction between } \\
\text { (chalcones+Schiff bases) }\end{array}$ & E/kJ.mol ${ }^{-1}$ & A $_{\text {A-factor } / \mathbf{s}^{-1}}$ & $\begin{array}{c}\Delta \mathrm{S} \neq / \mathrm{JK}^{-1} \mathrm{~mol}^{-1} \text { at } \\
308 \mathrm{~K}\end{array}$ \\
\hline \multicolumn{4}{|c|}{ Reaction of Chalcone A20 with substituted Schiff base $\left(B_{1}-B_{6}\right)$} \\
\hline A20+B1 & 55.21 10.03 & $8.02 \times 10^{6}$ & TS Cencerted \\
\hline $\mathrm{A20}+\mathrm{B2}$ & $50.45 \pm 0.02$ & $1.56 \times 10^{6}$ & -141.46 \\
\hline $\mathbf{A 2 0}+\mathbf{B 3}$ & $62.67 \neq 0.09$ & $6.92 \times 10^{7}$ & -98.31 \\
\hline $\mathrm{A20}+\mathrm{B4}$ & $64.56 \pm 0.08$ & $7.24 \times 10^{8}$ & -87.65 \\
\hline A20+B5 & $46.64 \pm 0.06$ & $4.62 \times 10^{5}$ & -164.24 \\
\hline $\mathrm{A20}+\mathrm{B} 6$ & $51.52 \pm 0.04$ & $3.47 \times 10^{6}$ & -137.43 \\
\hline
\end{tabular}




\section{Activation Parameters for the disappearance of intermediate}

For all of the reported unimolecular cyclization processes, it was observed that they are of low Arrhenius parameters with negative activation entropy. This was taken as evidence that the reaction proceeds through a cyclic activated complex rather than a linear biradical or zwitterion centres (Lewis and Steiner, 1964).

Table 6: Arrhenius parameters and entropies of activation for the reaction of Chalcone with Schiff base (B1-,B6) to cyclization of intermediate step1

\begin{tabular}{|c|c|c|c|}
\hline $\begin{array}{c}\text { Reaction between } \\
\text { (chalcones+Schiff bases) }\end{array}$ & E/kJ.mol ${ }^{-1}$ & A-factor $/ \mathbf{s}^{-1}$ & $\begin{array}{c}\Delta \mathrm{S} \neq / \mathrm{JK}^{-1} \mathrm{~mol}^{-1} \text { at } \\
308 \mathrm{~K}\end{array}$ \\
\hline \multicolumn{4}{|c|}{ Reaction of Chalcone A20 with substituted Schiff base $\left(B_{1}-B_{6}\right)$} \\
\hline A20+B1 & 34.96 & $1.93 \times 10^{4}$ & -171.52 \\
\hline $\mathrm{A20}+\mathrm{B} 2$ & 45.63 & $1.44 \times 10^{6}$ & -135.55 \\
\hline $\mathbf{A 2 0}+\mathbf{B 3}$ & 30.47 & $9.39 \times 10^{3}$ & -177.43 \\
\hline A20+B4 & 33.06 & $1.47 \times 10^{4}$ & -173.67 \\
\hline $\mathrm{A20}+\mathrm{B} 5$ & 46.52 & $3.56 \times 10^{6}$ & -127.81 \\
\hline $\mathrm{A20}+\mathrm{B} 6$ & 40.15 & $2.08 \times 10^{5}$ & -151.73 \\
\hline
\end{tabular}

\section{Correlation of information obtained from different techniques}

It is interesting to note that the only kinetic data yet known for the 1,3 cyclo addition of Schiff bases to chalcones, (with different substitution on the skeleton of both reactants), via the formation of an intermediate are those reported in the present work. The general scheme of our reaction was confirmed to be of the following type:

Chalcone + Schiff base $\longrightarrow$ Intermediate $\longrightarrow$ Pyrrolidine

The present work was carried out in the solution phase using three complementary types of techniques to follow the rates of the mechanistic steps as follows:

1- $\quad$ The formation of the intermediate was followed by fluorescence technique.

2- The rate of its cyclization to form the product was followed by UV technique.

The use of these different techniques can be illustrated by the following scheme:

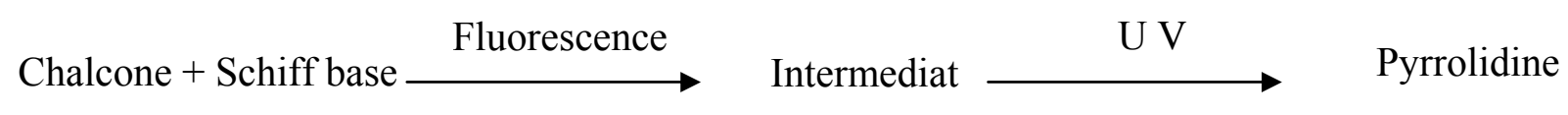




\section{1-Comparisons between the rates of different steps and processes}

In order to compare the rates of the different processes, the actual second order rate constants are required for the pseudo first order processes, since :

$$
k_{\text {observed }}=k_{\text {actual }}[\text { Schiff base conc. }]=k_{\text {actual }}\left[0.01 \mathrm{~mol} \mathrm{~L}^{-1}\right]
$$

therefore, all of the observed rate constants, that were estimated previously from the pseudo first order rate equation, must be divided by 0.01 in order to obtain the actual second order rate constants. Furthermore the time units of the different rate constants should be unified and expressed in $\left(\mathrm{s}^{-1}\right)$ for all used techniques.

The rate constants of the reactions $(\mathrm{A}+\mathrm{B} 1),(\mathrm{A}+\mathrm{B} 2)$ and $(\mathrm{A}+\mathrm{B} 3)$ at $30^{\circ} \mathrm{C}$ are chosen for comparison, as shown in the following table:

Table 7: The rate constants of the reactions chalcone with (B1-B3) at $30^{\circ} \mathrm{C}$ :

\begin{tabular}{|c|c|c|c|c|}
\hline Reaction & $\begin{array}{c}\text { Rate } \\
\text { constants }\end{array}$ & $\begin{array}{l}\text { Fluorescence } \\
\text { Formation of } \\
\text { Intermediate }\end{array}$ & $\begin{array}{c}\text { UV } \\
\text { Cyclization of } \\
\text { Intermediate } \\
\end{array}$ & $\begin{array}{l}\text { Ratio of } k_{\text {actual }} \\
\text { [form.]/[cycliz.] }\end{array}$ \\
\hline \multirow{2}{*}{$\begin{array}{c}(\mathrm{A} 20+\mathrm{B} 1) \\
\mathrm{X}=\mathrm{Y}=\mathrm{H}\end{array}$} & $k_{o b s}$ & $4.50 \times 10^{-4} \mathrm{~s}^{-1}$ & $2.73 \times 10^{-2} \mathrm{~min}^{-1}$ & \\
\hline & $10^{4} k_{\text {metwal }}$ & $450 \mathrm{M}^{-1} \mathrm{~s}^{-1}$ & $4.54 \mathrm{~s}^{-1}$ & 99.1 \\
\hline \multirow{2}{*}{$\begin{array}{c}(\mathrm{A} 20+\mathrm{B} 2) \\
\mathrm{X}=\mathrm{H}, \mathrm{Y}=\mathrm{p}- \\
\mathrm{OCH}_{3}\end{array}$} & $k_{a b s}$ & $13.0 \times 10^{-4} \mathrm{~s}^{-1}$ & $2.26 \times 10^{-2} \mathrm{~min}^{-1}$ & \\
\hline & $10^{4} k_{\text {axtual }}$ & $1300 \mathrm{M}^{-1} \mathrm{~s}^{-1}$ & $3.77 \mathrm{~s}^{-1}$ & 344.8 \\
\hline \multirow{2}{*}{$\begin{array}{c}(\mathrm{A} 20+\mathrm{B} 3) \\
\mathrm{X}=\mathrm{H}, \mathrm{Y}=\mathrm{p}- \\
\mathrm{NO}_{2}\end{array}$} & $k_{o b z s}$ & $2.03 \times 10^{-4} \mathrm{~s}^{-1}$ & $5.87 \times 10^{-2} \mathrm{~min}^{-1}$ & \\
\hline & $10^{4} k_{\text {artuat }}$ & $203 \mathrm{M}^{-1} \mathrm{~s}^{-1}$ & $9.78 \mathrm{~s}^{-1}$ & 20.8 \\
\hline
\end{tabular}

Comparisons of $k_{o b s}$, for reactions under study, of reactants with different substituents within the selected technique, i.e. comparisons of the effect of different substituents on the individual steps of the mechanism of the reactions under study, were performed previously.

The estimated values of $k_{\text {actual }}$, for the same above mentioned reactions, i.e. the actual rate constants of the subsequent steps of the mechanism that was obtained by different techniques, can now be compared with each other as follows:

1- Comparison between the rates of formation and cyclization (disappearance) of the intermediate, for all of the reactions, shows a very fast rate of formation. This may be attributed to a plausible approach of the Schiff base nucleophile toward the chalcone under study which can be explained in terms of polarizability of the latter. In fact the $\alpha, \beta$ unsaturated carbonyl system, (The chalcone), is characterized by its polarizability by localizing its positive charge mainly on $\mathrm{C}_{(4)}$ carbon in the $-\mathrm{C}_{(4)}=\mathrm{C}_{(3)}-\mathrm{C}_{(2)}=\mathrm{O}_{(1)}$ system due to the effective polarization of the negative oxygen atom. This effect sets the molecule to a nucleophilic attack. On the other hand, the approach of the Schiff base nucleophile toward $\beta$-carbon of the reaction centre gets facilitated by the presence of electron donating groups in $\mathrm{Y}$ position of the nucleophile, leading to a faster process of formation of the intermediate 
to occur relative to its decay. On the contrary the electron withdrawing group reduces the electronegativity of the nucleophile, thus reduces its ability to attack the reaction centre and decreases the rate of formation of the intermediate. Ratios of actual rate constants are in good agreement with this approach and support this suggestion.

2- The ratios of actual rate constants show clearly that electronic factors affect the rates of both processes (formation and cyclization of intermediate), but in an opposed direction. The presence of electron donating groups " $\mathrm{Y}$ " in para position of the nucleophile facilitates the formation of the intermediate due to the increase of the attraction forces with the partially positive reaction center of the chalcones, thus provides a better chance for the Schiff base nucleophile to attack in a rapid process, resulting into acceleration of the rate of this step. On the contrary, the same substituent "Y" will delay the cyclization process of the formed intermediate due to the increase of its nucleophilic nature, resulting into its stabilization. Moreover, the rotation of both sites of the intermediate ( chalcone and Schiff base sites ) around the newly formed single bond, which causes the exposure of the $\mathrm{sp}^{2}$ hybridized carbon to the nucleophilic attack, should also be taken into account. Presumably this process needs a time which may cause in lowering the chance of the cyclization process leading into a slow rate determining step.

3- On the other hand, the overall rate of formation of the product, for all of the above mentioned reactions, are also comparable with the rates of cyclization of the intermediate. Their values are very close to each other with slight differences which may be attributed to the difference in the procedure of handling the reactants in both techniques. This suggests that the formation of the product may also passes through a transition state similar to that of our formed intermediate. In fact, the formation of many five-membered heterocycles including pyrrolidine can proceed through a $(3+2)$ cycloaddition of allyl anions and olefins (Yamago et al., 1995). Computational studies showed that a concerted one step rapid process based on Woodward-Hoffmann rules is energetically less favorable than a slow process consisting of two-steps, similar to that suggested in our work.

\section{2- Comparisons between the activation energies of different steps and processes}

The activation parameters of both studied processes, i.e. direct formation of product and via the formation of intermediate, may also be taken into consideration. The Arrhenius parameters for both studied processes as summarized in the following Table were obtained from kinetic measurements at temperatures from 298-318 K. The entropies of activation are estimated from the A-factor at $35^{\circ} \mathrm{C}$.

The intermediate is, in fact, kinetically stable at the reaction temperature since it needs excess energy for its rotation around the formed single bond and its cyclization process to allow it to pass over the energy barrier to form the pyrrolidine product.

The use of different substituents shows obvious differences in activation energies of the different steps of the mechanism, as shown in the following table 
Table 8: The activation energies of different steps of the reactions chalcone with (B1-B3):

\begin{tabular}{|c|c|c|}
\hline Reaction & $\begin{array}{c}\text { Fluorescence } \\
\text { of Formation of } \\
\text { Intermediate } \\
/ \mathbf{~ k J ~ m o l}^{\mathbf{1}}\end{array}$ & $\begin{array}{c}\text { UV } \\
\mathbf{E}_{\mathbf{a}} \text { of Cyclization of } \\
\text { Intermediate } \\
/ \mathbf{~ k J ~ m o l}^{\mathbf{- 1}}\end{array}$ \\
\hline $\mathrm{A}+\mathrm{B} 1(\mathrm{Y}=\mathrm{H})$ & 55.21 & 34.96 \\
\hline $\mathrm{A}+\mathrm{B} 2\left(\mathrm{Y}=\mathrm{p}-\mathrm{OCH}_{3}\right)$ & 50.45 & 45.63 \\
\hline $\mathrm{A}+\mathrm{B} 3\left(\mathrm{Y}=\mathrm{p}-\mathrm{NO}_{2}\right)$ & 62.67 & 30.47 \\
\hline
\end{tabular}

\section{3- Nature of the transition states}

The entropy data, in particular, provide useful information about the configuration of the postulated transition states, (TS1 and TS2). The large negative values of $\Delta S_{1}^{*}, \Delta S_{2}^{*}$ and $\Delta S_{\text {overal }}^{*}$, as shown in Table (9), indicate that the transition states considerably suffer from less freedom of internal motion than the corresponding reactants. This can only happen when the configuration of the transition state TS1 is more aligned and rigidly formed than both of reactants, while TS2 is not very different in structure from the pyrrolidine molecule.

The values of A-factor reported in the present work are all identical in each used technique, suggesting that the configuration of the transition states of formation or cyclization are very similar, regardless the used substituent. This supports the precise measurements, using these different techniques that afforded accurate Arrhenius parameters.

Table 9: The values of $\Delta S^{\ddagger}$ of the reactions A20 with (B1-B3).

\begin{tabular}{|c|c|c|}
\hline Reaction & $\begin{array}{c}\text { Fluorescence } \\
\text { Form. of Intermediate }\end{array}$ & $\begin{array}{c}\text { UV } \\
\text { Decay of } \\
\text { Intermediate }\end{array}$ \\
\hline $\mathrm{A} 2+\mathrm{B} 1(\mathrm{Y}=\mathrm{H})$ & -260.57 & -258.13 \\
\hline $\mathrm{A}+\mathrm{B} 2(\mathrm{Y}=\mathrm{p}-\mathrm{OCH}$ & ) & -258.73 \\
\hline $\mathrm{A} 20+\mathrm{B} 3\left(\mathrm{Y}=\mathrm{p}-\mathrm{NO}_{2}\right)$ & -260.87 & -258.04 \\
\hline
\end{tabular}




\section{REFERENCES}

Clayden, G.; Warven and Wothers (2001). "Organic Chemistry", Oxford, pp. 234-237.

Gakce, E. ; Bakir, G. ; Sahin, M. F. ; Kupeli, E. ; Yesilada, E. (2005). Synthesis of new mannich bases of arylpyridazinones as analgesic and anti inflammatory agents. Arzneim. Forsch. 55, 318-325.

Jayashankaran, J.; Durga, R. ; Raghunathan, R. (2005). A facile entry into a novel class of dispiroheterocycles through 1,3-dipolar cycloaddition . ARKIVOC, 32-39.

Joule, J. A. ; Mills, K. (2010). " Heterocyclic Chemistry", 5th edn, Blackwell Publishing Ltd, $120 \mathrm{p}$.

Kauffmann, T.; Berg, H.; Koppelmann, E. (1970). Generation of 2-azaallyl anions by the transmetalation of $\mathrm{N}$-(trialkylstannyl)methanimines. Pyrrolidine synthesis by $[3+$ 2] cycloadditions with alkenes. Angew.Chem., 82, 396.

Kleingeld, J. C. ; Nibbering, N. M. (1984). The nucleophilic addition-elimination reaction on the carbonyl group of pivaloyl chloride, S-methyl thiopivaloate and 1-pivaloyl1,2,4-triazole in the gas phase. Recl. Trav. Chim. Pays-Bas. 103, 87.

Lewis, K. E. ; Steiner (1964). Electrocyclic reactions Stereochemistry of the triene electrocyclization. H., J. Chem. Soc., 3080.

Pearson, W. H. ; Szura, D. F. ; Postich, M. J. (1992). Application of the 2-azaalyl anion cycloaddition method to synthes of $( \pm)$-crinine and $( \pm)$ 6-epircinnine. J. Am. Chem. Soc. 114, 1329.

Powers, D. G.; Casebier, D.S.; Rayan, O.D.; Troth, W. J. ; Coffen, D.L. (1998). Microwave assisted solvent free synthesis of 1,3-diphenylpropenones. Tetrahedron. 54, 40854096.

Raj, A. A. ; Raghnathan, R. (2003). Synthesis of spiropyrrolidine via formal $(3,2)$ cycloaddition of unusual enones and cis-3benzoyl-1cyclohexyl-2-phenylaziridine, Tetrahedron. 59, 2907-2911.

Robinson, P. J. ; Holbrook K. A. (1972). "Unimolecular Reactions". Wiley-Interscience, London, $2006 \mathrm{p}$.

Vogel, A. (1989 ). "Practical Organic Chemistry". Longmans, 5th edn, 1034 p.

Waldmann, H. Synlett, (1995). "Organic Synthesis in Water". Thamson science, pappellallee, Weinheim, Germany, 133p.

Woodward, R. B. ; Hoffmann, R. (1969). The Conservation of Orbital Symmetry, Angew. Chem. 81, 797 . Internat.

Yamago, S. ; Ejiri, S.; Nakamura, E. (1995). ChemInform Abstract: A Concise Synthetic Route to Cyclopentenes by $(3+2)$ Cycloaddition of Dipolar Trimethylenemethane to Alkynes. Angew. Chem. 107, 2338. 